Article

\title{
Evaluation of Stability of Amylose Inclusion Complexes Depending on Guest Polymers and Their Application to Supramolecular Polymeric Materials
}

\author{
Tomonari Tanaka ${ }^{1, *}$, Atsushi Tsutsui ${ }^{1}$, Kazuya Tanaka ${ }^{2}$, Kazuya Yamamoto ${ }^{2}$ and \\ Jun-ichi Kadokawa ${ }^{2, *}$ \\ 1 Department of Biobased Materials Science, Graduate School of Science and Technology, \\ Kyoto Institute of Technology, Matsugasaki, Sakyo-ku, Kyoto 606-8585, Japan; atsushi.tsutsui@gmail.com \\ 2 Department of Chemistry, Biotechnology, and Chemical Engineering, \\ Graduate School of Science and Engineering, Kagoshima University, 1-21-40 Korimoto, \\ Kagoshima 860-0065, Japan; k1987386@kadai.jp (K.T.); yamamoto@eng.kagoshima-u.ac.jp (K.Y.) \\ * Correspondence: t-tanaka@kit.ac.jp (T.T.); kadokawa@eng.kagoshima-u.ac.jp (J.-I.K.); \\ Tel.: +81-75-724-7802 (T.T.); +81-99-285-7743 (J.-I.K.)
}

Academic Editor: Jürg Bähler

Received: 20 February 2017; Accepted: 9 March 2017; Published: 15 March 2017

\begin{abstract}
This paper describes the evaluation of the stability of amylose-polymer inclusion complexes under solution state in dimethyl sulfoxide (DMSO) depending on guest polymers. The three complexes were prepared by the vine-twining polymerization method using polytetrahydrofuran (PTHF), poly ( $\varepsilon$-caprolactone) (PCL), and poly(L-lactide) (PLLA) as guest polymers. The stability investigation was conducted at desired temperatures $\left(25,30,40,60^{\circ} \mathrm{C}\right)$ in DMSO solutions of the complexes. Consequently, the amylose-PTHF inclusion complex was dissociated at $25^{\circ} \mathrm{C}$, while the other complexes were stable under the same conditions. When the temperatures were elevated, the amylose-PCL and amylose-PLLA complexes were dissociated at 40 and $60{ }^{\circ} \mathrm{C}$, respectively. We also found that amylose inclusion supramolecular polymers which were prepared by the vine-twining polymerization using primer-guest conjugates formed films by the acetylation of amylose segments. The film from acetylated amylose-PLLA supramolecular polymer had higher storage modulus than that from acetylated amylose-PTHF supramolecular polymer, as a function of temperature.
\end{abstract}

Keywords: amylose; dissociation; film; inclusion complex; supramolecular polymer; vine-twining polymerization

\section{Introduction}

Amylose is an abundant natural polysaccharide as an energy resource present in starch [1]. Besides this vital role in nature, it is a well-known functional polymer and acts as a host molecule to form supramolecular inclusion complexes with various hydrophobic guest molecules, owing to its left-handed helical conformation and hydrophobic nature inside the cavity [2]. However, a limitation of binding directly toward polymeric guest molecules into the cavity has been found, because the driving force for complexation is implied by weak hydrophobic interaction [3-12]. We have developed an efficient method for the formation of inclusion complexes from amylose and polymeric guest molecules by means of enzymatic polymerization [13-20].

Amylose with well-defined structure is synthesized by enzymatic polymerization catalyzed by phosphorylase [21-24], as the enzymatic approach has been well accepted as a powerful tool to obtain polysaccharides with precisely controlled structure $[16,20,25]$. The phosphorylase-catalyzed enzymatic polymerization occurs by using $\alpha$-D-glucose 1-phoshate (G-1-P) as a monomer and 
maltooligosaccharide as a primer according to the following reversible reaction: $(\alpha(1 \rightarrow 4)-\mathrm{G})_{n}+$ G-1-P $\rightleftarrows(\alpha(1 \rightarrow 4)-G)_{n+1}+P$. In the reaction, a glucose $(G)$ residue is transferred from G-1-P to the non-reducing $4-\mathrm{OH}$ propagating terminus of a $\alpha(1 \rightarrow 4)$-glucan chain, liberating inorganic phosphate $(\mathrm{P})$. We have found that inclusion complexes are gradually formed with the progress of propagation when the phosphorylase-catalyzed enzymatic polymerization was carried out in the presence of hydrophobic guest polymers dispersed in an aqueous buffer solvent (Figure 1a) [13-20]. The process of propagation from the shorter $\alpha(1 \rightarrow 4)$-glucan chain (maltooligosaccharide primer) to the longer $\alpha(1 \rightarrow 4)$-glucan chain (amylose) efficiently induces complexation with polymeric guest molecules. As the process of such complexation is similar to the way that vines of plants grow twining around a rod, the authors have named this polymerization approach "vine-twining polymerization". In previous studies, hydrophobic polyethers such as polytetrahydrofuran (PTHF) [26,27] and hydrophobic polyesters such as poly( $\varepsilon$-caprolactone) (PCL) and poly(L-lactide) (PLLA) [28-30] have been found to form inclusion complexes with amylose by the vine-twining polymerization (Figure 1a).

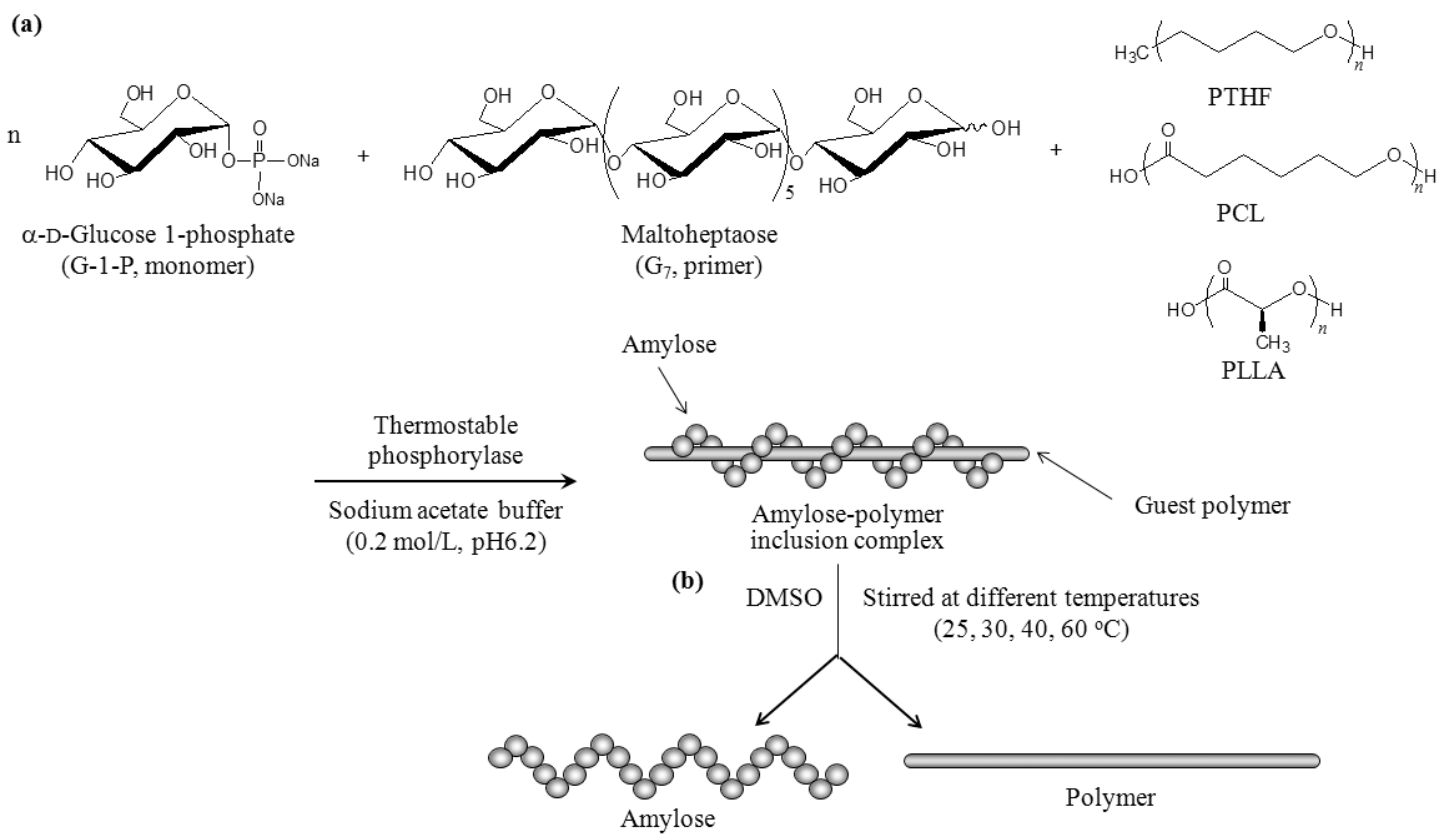

Figure 1. Preparation of: (a) inclusion complexes by vine-twining polymerization using polytetrahydrofuran (PTHF), poly(E-caprolactone) (PCL), and poly(l-lactide) (PLLA) as guest polymers and (b) their dissociation under solution state in dimethyl sulfoxide (DMSO).

By means of the vine-twining polymerization method, we have achieved the synthesis of inclusion supramolecular polymers which are composed of a continuum of the amylose-PTHF and amylose-PLLA inclusion complexes [31-34]. When primer (maltoheptaose, $\mathrm{G}_{7}$ )-guest conjugate substrates $\left(\mathrm{G}_{7}-\mathrm{PTHF}\right.$ and $\left.\mathrm{G}_{7}-\mathrm{PLLA}\right)$ were used in the vine-twining polymerization, where the termini of the guest polymers were covalently connected with the reducing end of $G_{7}$ via a triazole ring (Figure 2a), a propagating amylose chain which was started from the $\mathrm{G}_{7}$ segment in the $\mathrm{G}_{7}$-guest conjugate by the phosphorylase catalysis included the guest segment in the other substrate. This special type of the vine-twining polymerization among the substrates successively takes place, giving rise to the inclusion supramolecular polymers composed of amylose and guest polymer PTHF or PLLA. 
(a)

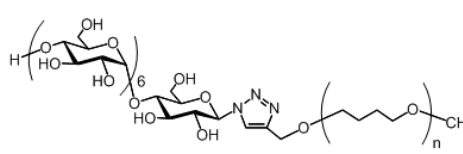

$\mathrm{G}_{7}-\mathrm{PTHF}$

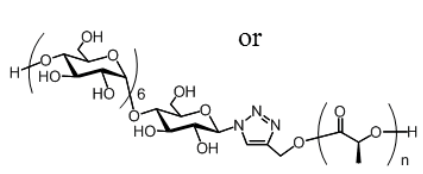

Vine-twining polymerization

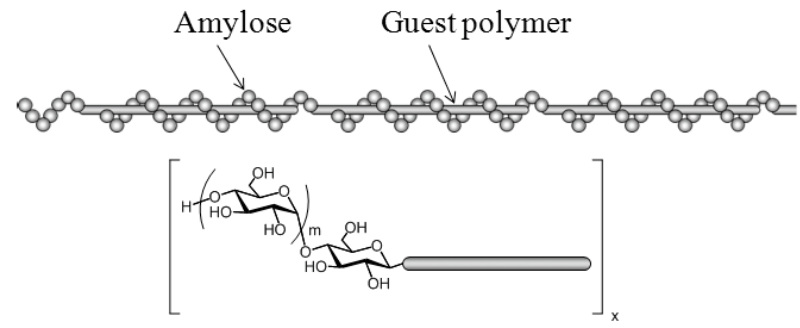

$\mathrm{G}_{7}$-PLLA

Amylose inclusion supramolecular polymer

(b)

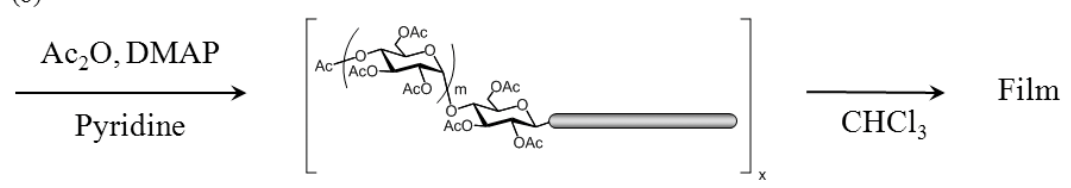

ATA inclusion supramolecular polymer

Figure 2. Preparation of: (a) amylose triacetate (ATA) inclusion supramolecular polymers and (b) their films. DMAP: N,N-dimethyl-4-aminopyridine.

To understand the natures of amylose-polymer inclusion complexes further, in this study we investigated the evaluation of their stability under solution state in dimethyl sulfoxide (DMSO) depending on guest polymers. On the basis of the findings, we also evaluated the mechanical properties of amylose triacetate (ATA)-PTHF and ATA-PLLA supramolecular polymeric films as a function of temperature, which were found to be obtained by acetylation of the original amylose inclusion supramolecular polymers. In a previous study, we also prepared a supramolecular film via the formation of a hydrogel by the vine-twining polymerization approach using the appropriately designed graft copolymer (i.e., carboxymethyl cellulose-graft-PCL) [35]. In this system, the enzymatically produced amyloses formed inclusion complexes with grafted PCL chains in the intermolecular graft copolymers, which acted as cross-linking points, resulting in network structures. Such network structures contributed to forming the hydrogel from the vine-twining polymerization solution, which was easily converted into the supramolecular film by drying. The present study provides a new type of supramolecular film constructed from linear polymeric structures, which are based on a completely different preparative strategy from that of the previous study.

\section{Results and Discussion}

\subsection{Evaluation of the Stability of Inclusion Complexes Under Solution State}

The amylose-polymer inclusion complexes were prepared by vine-twining polymerization using PTHF (Number-average molecular weight $\left(M_{\mathrm{n}}\right)=2800$ by ${ }^{1} \mathrm{H}$ nuclear magnetic resonance (NMR)), $\operatorname{PCL}\left(M_{\mathrm{n}}=2400\right.$ by ${ }^{1} \mathrm{H}$ NMR $)$, and PLLA $\left(M_{\mathrm{n}}=2600\right.$ by ${ }^{1} \mathrm{H}$ NMR $)$ according to literature procedures (Figure 1a) $[27,29,30]$. The structures of the inclusion complexes were supported by the ${ }^{1} \mathrm{H}$ NMR spectra (see Materials and Methods section). The X-ray diffraction (XRD) patterns of the products were identical with those of the literature data; $2 \theta=\mathrm{ca}$. 13 and $20^{\circ}$ for $6_{1}$-helix from PTHF and PCL, $2 \theta=\mathrm{ca}$.

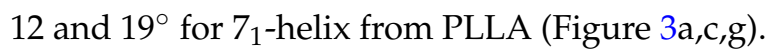




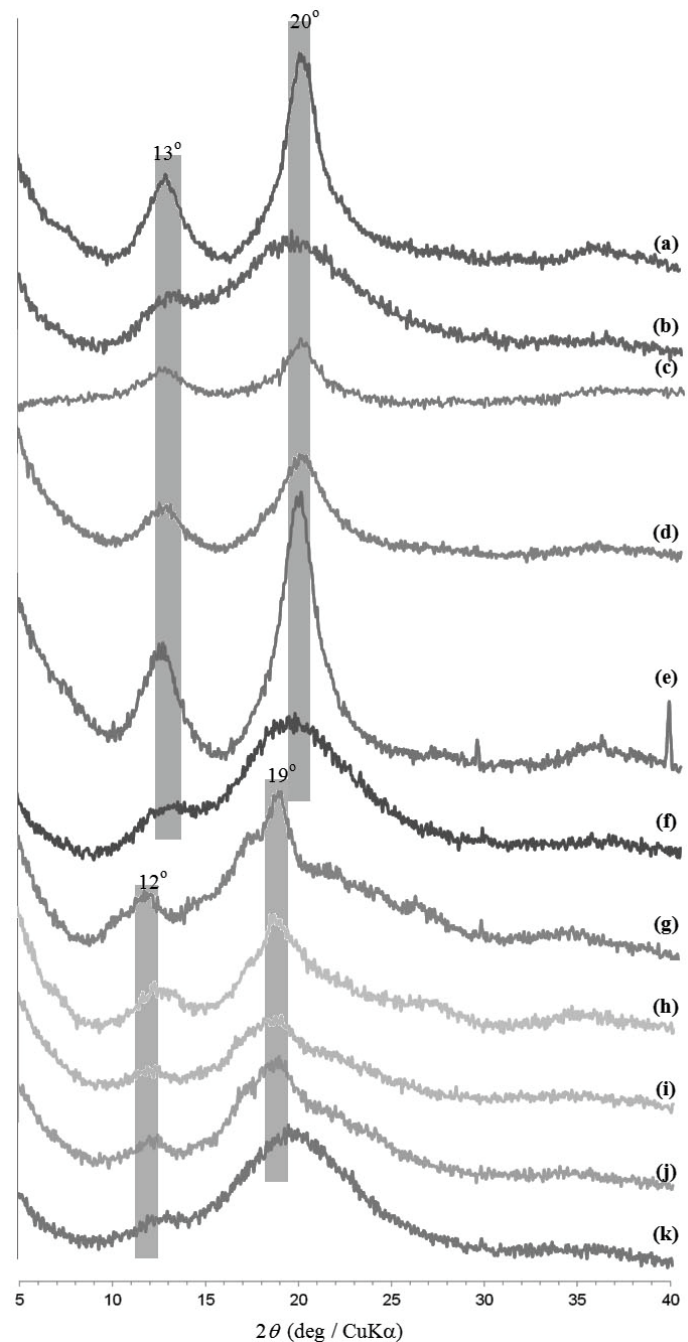

Figure 3. X-ray diffraction (XRD) profiles of: (a) amylose-PTHF inclusion complex; (b) chloroform-insoluble fraction by its treatment in DMSO at $25^{\circ} \mathrm{C}$; (c) amylose-PCL inclusion complex, chloroform-insoluble fractions by its treatment in DMSO at (d) $25^{\circ} \mathrm{C}$, (e) $30^{\circ} \mathrm{C}$, and (f) $40^{\circ} \mathrm{C}$; (g) amylose-PLLA inclusion complex, chloroform-insoluble fractions by its treatment in DMSO at (h) $25^{\circ} \mathrm{C}$, (i) $30^{\circ} \mathrm{C},(\mathbf{j}) 40{ }^{\circ} \mathrm{C}$, and (k) $60{ }^{\circ} \mathrm{C}$.

As the inclusion complexes were soluble in DMSO, the stability investigations under solution state were conducted in DMSO. After the inclusion complexes were treated in DMSO for $12 \mathrm{~h}$ at desired temperatures, the products were separated into chloroform-soluble and -insoluble fractions (Figure 1b). The XRD pattern of the chloroform-insoluble fraction after the treatment of the amylose-PTHF inclusion complex at $25{ }^{\circ} \mathrm{C}$ was broadened, which is completely different from that before treatment (Figure 3a,b). On the other hand, the XRD patterns of the chloroform-insoluble fractions from the other complexes remained intact by treatment at $25^{\circ} \mathrm{C}$ (Figure $3 \mathrm{c}, \mathrm{d}, \mathrm{g}, \mathrm{h}$ ). These results indicate that the dissociation of the amylose-PTHF inclusion complex probably occurred, while the amylose-PCL and -PLLA inclusion complexes were stable at that temperature. Indeed, the ${ }^{1} \mathrm{H}$ NMR spectrum of the chloroform-insoluble fraction $\left(0.5 \mathrm{M} \mathrm{NaOD} / \mathrm{D}_{2} \mathrm{O}\right)$ from the amylose-PTHF inclusion complex shows signals assignable to amylose, but does not show signals due to PTHF (Figure 4a). Furthermore, the ${ }^{1} \mathrm{H}$ NMR spectrum of the chloroform-soluble fraction $\left(\mathrm{CDCl}_{3}\right)$ from the same complex supports the structure of PTHF (Figure 5a). 


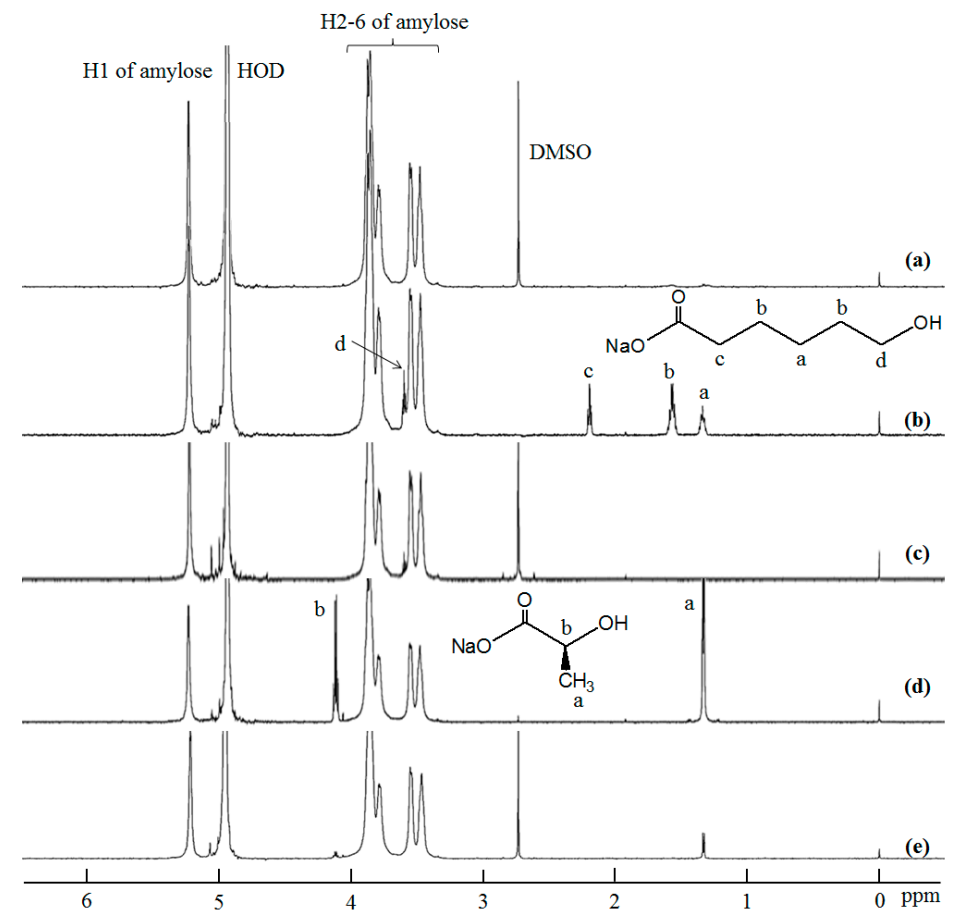

Figure 4. ${ }^{1} \mathrm{H}$ nuclear magnetic resonance (NMR) spectra of: (a) chloroform-insoluble fraction by treatment of amylose-PTHF inclusion complex in DMSO at $25^{\circ} \mathrm{C}$; chloroform-insoluble fractions by treatment of amylose-PCL inclusion complex in DMSO at (b) $30^{\circ} \mathrm{C}$ and (c) $40^{\circ} \mathrm{C}$; and chloroform-insoluble fractions by treatment of amylose-PLLA inclusion complex in DMSO at (d) $40{ }^{\circ} \mathrm{C}$ and (e) $60{ }^{\circ} \mathrm{C}(0.5 \mathrm{M}$ $\left.\mathrm{NaOD} / \mathrm{D}_{2} \mathrm{O}\right)$.

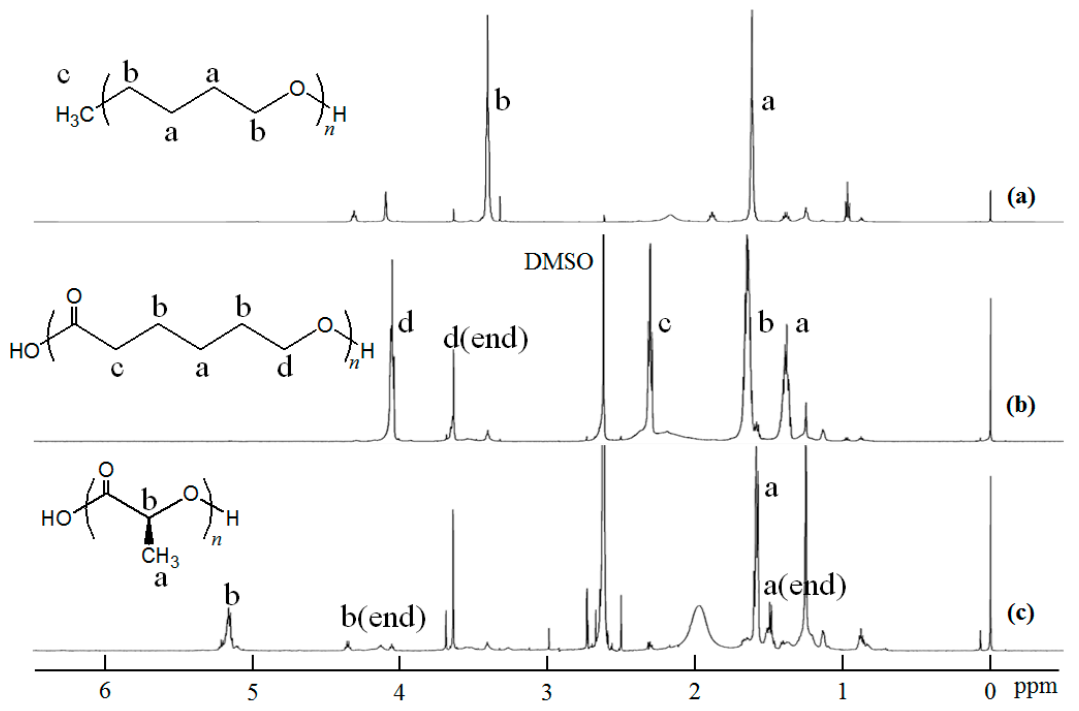

Figure 5. ${ }^{1} \mathrm{H}$ NMR spectra of: (a) chloroform-soluble fraction by treatment of amylose-PTHF inclusion complex in DMSO at $25^{\circ} \mathrm{C}$; (b) chloroform-soluble fraction by treatment of amylose-PCL inclusion complex in DMSO at $40^{\circ} \mathrm{C}$; and (c) chloroform-soluble fraction by treatment of amylose-PLLA inclusion complex in DMSO at $60{ }^{\circ} \mathrm{C}\left(\mathrm{CDCl}_{3}\right)$.

By elevating the treatment temperature of the amylose-PCL inclusion complex to $30{ }^{\circ} \mathrm{C}$, the XRD pattern of the chloroform-insoluble fraction was not significantly changed from the original pattern (Figure 3e). Moreover, the ${ }^{1} \mathrm{H}$ NMR spectrum of the same sample $\left(0.5 \mathrm{M} \mathrm{NaOD} / \mathrm{D}_{2} \mathrm{O}\right)$ showed signals 
assignable to both amylose and 6-hydroxycaproic acid sodium salt (the hydrolyzed product from PCL under alkaline condition in $0.5 \mathrm{M} \mathrm{NaOD} / \mathrm{D}_{2} \mathrm{O}$ ) (Figure $4 \mathrm{~b}$ ), supporting that the inclusion complex retains stability after treatment at that temperature. When the treatment temperature of this inclusion complex was elevated to $40^{\circ} \mathrm{C}$, the XRD pattern of the chloroform-insoluble fraction was broadened (Figure $3 \mathrm{f}$ ) as same as that treated from the amylose-PTHF inclusion complex at $25^{\circ} \mathrm{C}$. The ${ }^{1} \mathrm{H}$ NMR spectrum of this fraction $\left(0.5 \mathrm{M} \mathrm{NaOD} / \mathrm{D}_{2} \mathrm{O}\right)$ only showed a signal assignable to amylose (Figure $\left.4 \mathrm{c}\right)$, whereas the ${ }^{1} \mathrm{H}$ NMR spectrum of the chloroform-soluble fraction $\left(\mathrm{CDCl}_{3}\right)$ supports the structure of PCL (Figure 5b). These results suggest that the amylose-PCL inclusion complex was dissociated by treatment in DMSO at $40{ }^{\circ} \mathrm{C}$.

When the treatment temperatures of the amylose-PLLA inclusion complex were elevated up to $40{ }^{\circ} \mathrm{C}$, the XRD patterns of the chloroform-insoluble fractions were not significantly changed from the original data (Figure $3 \mathrm{~h}-\mathrm{j}$ ). Furthermore, in the ${ }^{1} \mathrm{H}$ NMR spectrum of the chloroform-insoluble fraction by the treatment at $40{ }^{\circ} \mathrm{C}$ in $0.5 \mathrm{M} \mathrm{NaOD} / \mathrm{D}_{2} \mathrm{O}$ (Figure $4 \mathrm{~d}$ ), the signals due to both amylose and L-lactic acid sodium salt (the hydrolyzed product from PLLA under alkaline condition in $0.5 \mathrm{M}$ $\mathrm{NaOD} / \mathrm{D}_{2} \mathrm{O}$ ) are detected. By further elevating the treatment temperature of the amylose-PLLA inclusion complex to $60{ }^{\circ} \mathrm{C}$, the XRD pattern of the chloroform-insoluble fraction is broadened, which is completely different from that before treatment (Figure $3 \mathrm{~h}, \mathrm{k}$ ). Indeed, the signals assignable to amylose are only detected in the ${ }^{1} \mathrm{H}$ NMR spectrum of this fraction $\left(0.5 \mathrm{M} \mathrm{NaOD} / \mathrm{D}_{2} \mathrm{O}\right)$ (Figure $\left.4 \mathrm{e}\right)$. Furthermore, the ${ }^{1} \mathrm{H}$ NMR spectrum of the chloroform-soluble fraction $\left(\mathrm{CDCl}_{3}\right)$ supports the structure of PLLA (Figure 5c). These results indicate the occurrence of the dissociation of the amylose-PLLA inclusion complex by treatment in DMSO at $60^{\circ} \mathrm{C}$.

Based on the above results, we conclude the following order for the stability of the inclusion complexes under solution state in DMSO: amylose-PLLA inclusion complex > amylose-PCL inclusion complex $>$ amylose-PTHF inclusion complex. The difference in stability of the complexes is probably owing to the bulkiness of the guest polymers. The slenderest structure of PTHF induces the easier dissociation of the complex. With increasing the bulkiness by incorporating carbonyl groups into the PCL and PLLA main-chains and further methyl group into the PLLA main-chain, the guest polymers slip out from cavity of amylose less easily, leading to an enhancement of the stability of the complex in DMSO.

\subsection{Preparation and Mechanical Properties of ATA Supramolecular Polymeric Films}

Based on the above results, we also investigated the evaluation of the mechanical properties of ATA-PTHF and -PLLA supramolecular polymeric materials as a function of temperature. We found that the supramolecular polymeric films were obtained by acetylation of amylose segments, which were suitably subjected to dynamic mechanical analysis (DMA) measurement for the evaluation. The ATA supramolecular polymers were prepared from amylose-PTHF and -PLLA inclusion supramolecular polymers which were synthesized by the vine-twining polymerization using $\mathrm{G}_{7}-\mathrm{PTHF}$ and $\mathrm{G}_{7}-\mathrm{PLLA}$, respectively $[31,33]$, by the acetylation reaction using acetic anhydride $\left(\mathrm{Ac}_{2} \mathrm{O}\right)$ in pyridine in the presence of $N, N$-dimethyl-4-aminopyridine (DMAP) (Figure $2 b$ ). The ${ }^{1} \mathrm{H}$ NMR spectra of the acetylated products showed signals assignable to the methyl of introduced acetyl groups, the acetylated amylose, and the guest polymer segments (Figure 6). The degrees of substitution on hydroxy groups by acetyl groups were determined by the ${ }^{1} \mathrm{H}$ NMR spectra to be quantitative in both the supramolecular polymers. Figure 7 shows the gel permeation chromatography (GPC) traces of acetylated products, which show peaks with unimodal profiles. The $M_{\mathrm{n}}$ values of ATA-PTHF and -PLLA supramolecular products were calculated to be $1.3 \times 10^{5} \mathrm{~g} \cdot \mathrm{mol}^{-1}$ (Weight-average molecular weight $\left(M_{\mathrm{W}}\right) / M_{\mathrm{n}}=3.6$ ) and $5.4 \times 10^{5} \mathrm{~g} \cdot \mathrm{mol}^{-1}\left(M_{\mathrm{w}} / M_{\mathrm{n}}=5.2\right)$, respectively. The $M_{\mathrm{n}}$ values of primer-guest conjugate substrates $\left(\mathrm{G}_{7}-\mathrm{PTHF}\right.$ and $\left.\mathrm{G}_{7}-\mathrm{PLLA}\right)$ used for the vine-twining polymerization were much smaller $\left(3.3 \times 10^{3} \mathrm{~g} \cdot \mathrm{mol}^{-1}\right.$ and $2.8 \times 10^{3} \mathrm{~g} \cdot \mathrm{mol}^{-1}$, respectively $)$, suggesting that the inclusion complexation by amylose in the supramolecular polymers was not dissociated under the acetylation condition. 
(a)

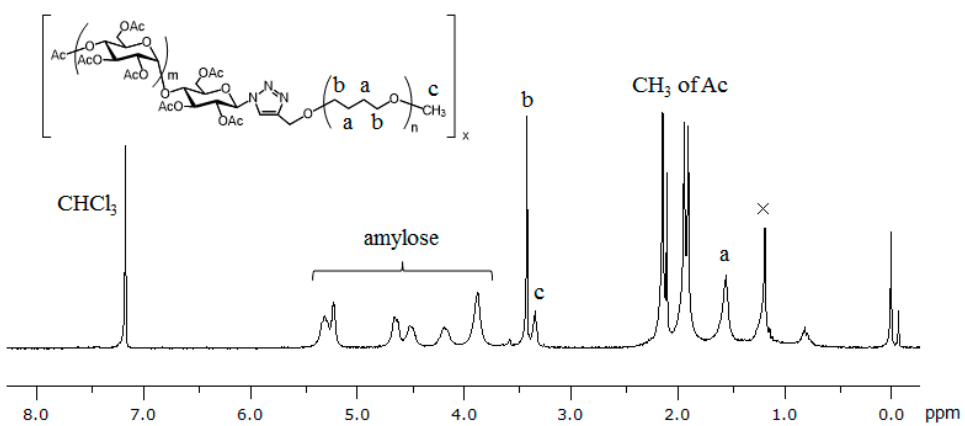

(b)

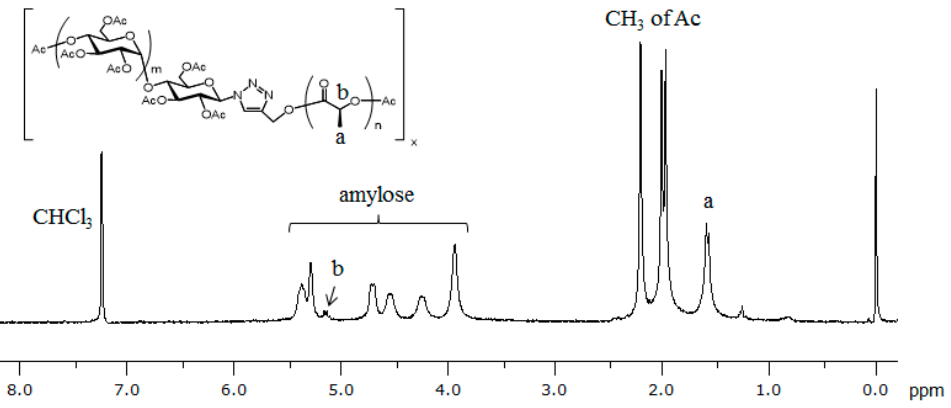

Figure 6. ${ }^{1} \mathrm{H}$ NMR spectra of: (a) ATA-PTHF and (b) ATA-PLLA supramolecular polymers $\left(\mathrm{CDCl}_{3}\right)$.

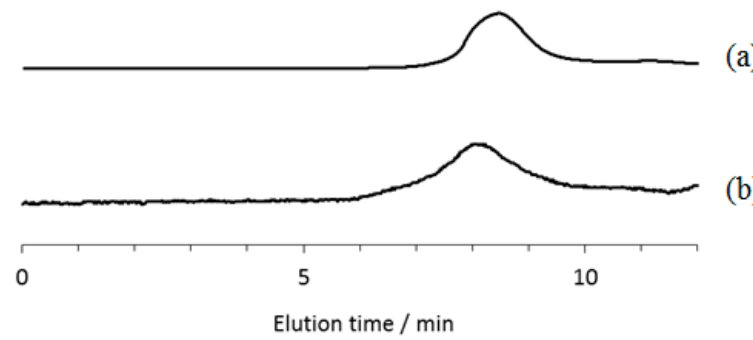

Figure 7. Gel permeation chromatography (GPC) traces of (a) ATA-PTHF and (b) ATA-PLLA supramolecular polymers.

We found that the present ATA inclusion supramolecular polymers were soluble in common organic solvents and could easily form films, although the amylose-polymer supramolecular polymers before acetylation were mostly insoluble in such organic solvents. Accordingly, flexible cast films were obtained from chloroform solutions of the ATA-PTHF and -PLLA supramolecular products. Figure 8 shows the DMA measurements of the resulting films from ATA supramolecular polymers and potato ATA $\left(M_{\mathrm{n}}=1.8 \times 10^{5} \mathrm{~g} \cdot \mathrm{mol}^{-1}, M_{\mathrm{w}} / M_{\mathrm{n}}=7.2\right.$ by GPC), which was prepared by the same acetylation procedure from a commercial potato amylose sample. Storage moduli $\left(\mathrm{E}^{\prime}\right)$ of the ATA-PLLA supramolecular polymeric film were higher than those of the ATA-PTHF supramolecular polymeric film and potato ATA on the whole temperature range. The descent curve of $\mathrm{E}^{\prime}$ of the ATA-PLLA supramolecular polymeric film shifted to the higher temperature region compared with that of the ATA-PTHF supramolecular polymeric film and potato ATA (Figure 8a), suggesting that PLLA segments included by amylose had enhanced the stability of the supramolecular polymeric film under heating. $\mathrm{E}^{\prime}$ of the ATA-PTHF supramolecular polymeric film dropped off at $150{ }^{\circ} \mathrm{C}$, suggesting that the inclusion by amylose might be dissociated in the ATA-PTHF supramolecular polymeric film under heating. There is no such behavior in the case of the ATA-PLLA supramolecular polymeric film. Furthermore, loss moduli $\left(E^{\prime \prime}\right)$ of the ATA-PLLA supramolecular polymeric film are shown to be higher than those of the ATA-PTHF supramolecular polymeric film at $150-165{ }^{\circ} \mathrm{C}$ (Figure $8 \mathrm{~b}$ ). These 
DMA results support that the film from ATA-PLLA supramolecular polymer is more stable at high temperature than that from ATA-PTHF supramolecular polymer and potato ATA.

(a)

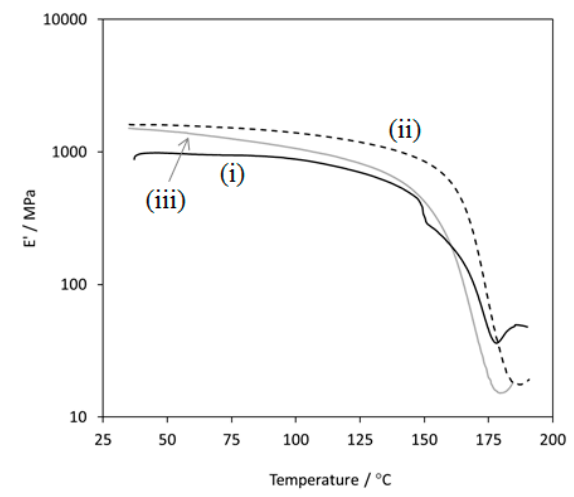

(b)

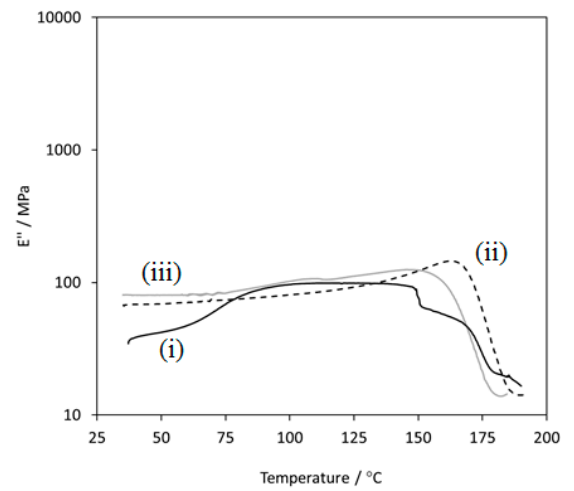

Figure 8. Dynamic mechanical analysis of (i) ATA-PTHF and (ii) ATA-PLLA supramolecular polymeric films, and (iii) potato ATA. (a) storage modulus ( $\left.\mathrm{E}^{\prime}\right)$; (b) loss modulus $\left(\mathrm{E}^{\prime \prime}\right)$.

\section{Materials and Methods}

\subsection{Materials}

The primer $\mathrm{G}_{7}$ was prepared by selective cleavage of one glucosidic bond of $\beta$-cyclodextrin under acidic conditions [36]. The guest polymers PTHF, PCL, and PLLA were synthesized by ring-opening polymerization of tetrahydrofuran, $\varepsilon$-caprolactone, and L-lactide monomers initiated with methyl trifluoromethanesulfonate, 6-hydroxycaproic acid, and L-lactic acid, respectively [37-39]. Amylose-PTHF and -PLLA inclusion supramolecular polymers were synthesized according to the literature procedures [31,33]. Thermostable phosphorylase from Aquifex aeolicus VF5 was supplied from Ezaki Glico Co. Ltd. (Osaka, Japan) [23,40,41]. Potato amylose was purchased from Sigma-Aldrich Co. LLC. (St. Louis, MO, USA). Other reagents and solvents were commercially available and used without further purification.

\subsection{Preparation of Amylose-Polymer Inclusion Complexes}

A typical experimental procedure was as follows. A mixture of the guest polymer (50 mg) with sodium acetate buffer ( $\mathrm{pH} 6.2,0.2 \mathrm{~mol} / \mathrm{L}, 4.0 \mathrm{~mL}$ ) was sonicated to obtain a dispersion. After the addition of $\mathrm{G}_{7}(1.2 \mathrm{mg}, 1.0 \mathrm{mmol}), \mathrm{G}-1-\mathrm{P}$ disodium salt $(76.1 \mathrm{mg}, 0.25 \mathrm{mmol})$, and thermostable phosphorylase $(9 \mathrm{U})$ to the suspension, the mixture was stirred vigorously for $15 \mathrm{~h}$ at $40-45^{\circ} \mathrm{C}$. The precipitate was collected by filtration, washed with water, acetone, and chloroform, and then dried under reduced pressure at room temperature to yield the inclusion complex. ${ }^{1} \mathrm{H}$ NMR spectra (DMSO- $d_{6}+\mathrm{D}_{2} \mathrm{O}$ ): amylose-PTHF inclusion complex; $\delta 1.48-1.55$ (br, $-\mathrm{C}-\mathrm{CH}_{2}-\mathrm{CH}_{2}-\mathrm{C}-$ of PTHF), 3.15-3.66 (m, H2- H6 of amylose, overlapping with $\mathrm{HOD}), 3.30-3.37$ (br, $\mathrm{O}-\mathrm{CH}_{2}-\mathrm{C}-\mathrm{C}-\mathrm{CH}_{2}-$ of PTHF), 5.11 (br, $\mathrm{H} 1$ of amylose); amylose-PCL inclusion complex; $\delta 1.33-1.36$ (br, $\mathrm{O}=\mathrm{C}-\mathrm{C}-\mathrm{C}-\mathrm{CH}_{2}$ of PCL), 1.55-1.59 (br, $\mathrm{O}=\mathrm{C}-\mathrm{C}-\mathrm{CH}_{2}-\mathrm{C}-\mathrm{CH}_{2}$ of PCL), 2.19-2.20 (br, $\mathrm{O}=\mathrm{C}-\mathrm{CH}_{2}$ of PCL), 3.15-3.66 (m, $\mathrm{H} 2-\mathrm{H} 6$ of amylose, overlapping with HOD), 3.58-3.60 (br, $\mathrm{C}-\mathrm{CH}_{2}-\mathrm{OH}$ of PCL (terminus)), 4.02-4.22 (br, $\mathrm{C}-\mathrm{CH}_{2}-\mathrm{O}-$ of PCL), 5.11 (br, $\mathrm{H} 1$ of amylose); amylose-PLLA inclusion complex; $\delta 1.45-1.48$ (m, $\mathrm{CH}_{3}$ of PLLA), 3.15-3.66 (m, H2-H6 of amylose, overlapping with HOD), 5.11 (br, H1 of amylose), 5.20-5.22 (br, CH of PLLA).

\subsection{Evaluation of the Stability of Inclusion Complexes}

Mixtures of the aforementioned inclusion complexes $(60 \mathrm{mg})$ with DMSO $(4 \mathrm{~mL})$ were stirred for $12 \mathrm{~h}$ at desired temperatures $\left(25,30,40,60^{\circ} \mathrm{C}\right)$. Chloroform was then added to the mixtures to obtain 
precipitates. The precipitates were isolated by filtration and dried under reduced pressure for $3 \mathrm{~h}$ at room temperature. The filtrates were concentrated by evaporation and dried under reduced pressure for $5 \mathrm{~h}$ at $110{ }^{\circ} \mathrm{C}$. The resulting two fractions were then characterized.

\subsection{Preparation of ATA Inclusion Supramolecular Polymeric Films}

A typical experimental procedure was as follows. $\mathrm{Ac}_{2} \mathrm{O}(0.27 \mathrm{~mL}, 2.86 \mathrm{mmol})$ was dropped to a mixture of the amylose-polymer inclusion supramolecular polymer (30 mg), DMAP (2 mg, $0.016 \mathrm{mmol})$, and pyridine $(0.5 \mathrm{~mL})$, followed by stirring for 3 days at room temperature. The reaction mixture was diluted with dichloromethane, and extracted with saturated sodium dicarbonate aqueous solution, $1 \mathrm{M}$ hydrochloride aqueous solution, and brine. The organic layer was dried with sodium sulfate, and the filtrate was dried under reduced pressure to yield the ATA inclusion supramolecular polymer. ${ }^{1} \mathrm{H}$ NMR spectra $\left(\mathrm{CDCl}_{3}\right)$ : ATA-PTHF supramolecular polymer; $\delta 1.55\left(\mathrm{br},-\mathrm{C}-\mathrm{CH}_{2}-\mathrm{CH}_{2}-\mathrm{C}-\right.$ of PTHF), 1.91-2.15 (m, $\mathrm{CH}_{3}$ of Ac), 3.34 (br, $\left.\mathrm{OCH}_{3}\right), 3.42$ (br, O- $\mathrm{CH}_{2}-\mathrm{C}-\mathrm{C}-\mathrm{CH}_{2}-\mathrm{O}$ of PTHF), 3.89 , 4.20, 4.52, 4.67, 5.24, and 5.33 (amylose); ATA-PLLA supramolecular polymer; $\delta 1.59$ (br, $\mathrm{CH}_{3}$ of PLLA), 1.98-2.21 (m, $\mathrm{CH}_{3}$ of Ac), 3.95, 4.27, 4.55, 4.72, 5.30, and 5.39 (amylose), 5.16 (q, CH of PLLA). The films were prepared by casting chloroform solutions $(33 \mathrm{mg} / \mathrm{mL})$ of the resulting ATA inclusion supramolecular polymers on a glass plate, and dried at room temperature.

\subsection{Measurements}

The ${ }^{1} \mathrm{H}$ NMR spectra were recorded using a ECX400 (JEOL, Akishima, Tokyo, Japan), ECA600 (JEOL), and a BioSpin AV-300 spectrometer (Bruker, Yokohama, Kanagawa, Japan). The powder XRD measurements were performed using a X'Pert Pro MPD diffractometer (PANalytical B.V., Almelo, The Netherlands) with Ni-filtered $\mathrm{Cu} \mathrm{K} \alpha$ radiation $(\lambda=0.15418 \mathrm{~nm})$. GPC measurements were conducted using a system consisting of a LC-20AD pump (Shimadzu, Kyoto, Japan), a CTO-10A column oven, an RID-10A refractive index detector, and two TSK gel Super HZM-N $(4.6 \times 150 \mathrm{~mm}$; TOSOH, Tokyo, Japan) columns. Chloroform was used as the eluent at a flow rate of $0.25 \mathrm{~mL} / \mathrm{min}$ at $40{ }^{\circ} \mathrm{C}$. Polystyrene samples were used as standards. The DMA were performed using a DMA 2980 Dynamic Mechanical Analyzer (TA Instruments, Tokyo, Japan) at heating rate of $5{ }^{\circ} \mathrm{C} / \mathrm{min}$ at $1 \mathrm{~Hz}$ using a supramolecular polymeric film $(5 \mathrm{~mm} \times 20 \mathrm{~mm})$.

\section{Conclusions}

In this paper, we reported the evaluation of the stability of amylose-polymer inclusion complexes under solution state in DMSO. The analytical results of the products indicated that stability in the DMSO solutions increased in accordance with the bulkiness of the guest polymers as follows: PTHF $<$ PCL < PLLA. Furthermore, we achieved preparation of ATA inclusion supramolecular films from the vine-twining supramolecular polymeric products by acetylation of amylose segments. The DMA analysis indicated that the dynamic moduli of the film from ATA inclusion supramolecular polymer depended on the type of included guest polymers.

Acknowledgments: We acknowledge the supplement of thermostable phosphorylase from Ezaki Glico Co. Ltd, Osaka, Japan. This work was financially supported by a research grant from The Mazda Foundation (No. 14KK-122).

Author Contributions: Tomonari Tanaka, Kazuya Yamamoto, and Jun-ichi Kadokawa conceived the project, designed the experiments, directed the research, and wrote the manuscript. Atsushi Tsutsui and Kazuya Tanaka performed the experiments. All authors discussed the results and edited the manuscript.

Conflicts of Interest: The authors declare no conflict of interest.

\section{References}

1. Schuerch, C. Polysaccharides. In Encyclopedia of Polymer Science and Engineering, 2nd ed.; Mark, H.F., Bilkales, N., Overberger, C.G., Eds.; John Wiley \& Sons: New York, NY, USA, 1986; Volume 13, pp. 87-162. 
2. Putseys, J.A.; Lamberts, L.; Delcour, J.A. Amylose-inclusion complexes: Formation, identity and physico-chemical properties. J. Cereal Sci. 2010, 51, 238-247. [CrossRef]

3. Shogren, R.L.; Greene, R.V.; Wu, Y.V. Complexes of starch polysaccharides and poly(ethylene-co-acrylic acid): Structure and stability in solution. J. Appl. Polym. Sci. 1991, 42, 1701-1709. [CrossRef]

4. Shogren, R.L. Complexes of starch with telechelic poly(e-caprolactone) phosphate. Carbohydr. Polym. 1993, 22, 93-98. [CrossRef]

5. Star, A.; Steuerman, D.W.; Heath, J.R.; Stoddart, J.F. Starched carbon nanotubes. Angew. Chem. Int. Ed. 2002, 41, 2508-2512. [CrossRef]

6. Ikeda, M.; Furusho, Y.; Okoshi, K.; Tanahara, S.; Maeda, K.; Nishino, S.; Mori, T.; Yashima, E. A luminescent poly(phenylenevinylene)-amylose composite with supramolecular liquid crystallinity. Angew. Chem. Int. Ed. 2006, 45, 6491-6495. [CrossRef] [PubMed]

7. Kida, T.; Minabe, T.; Okabe, S.; Akashi, M. Partially-methylated amyloses as effective hosts for inclusion complex formation with polymeric guests. Chem. Commun. 2007, 1559-1561. [CrossRef] [PubMed]

8. Kaneko, Y.; Kyutoku, T.; Shimomura, N.; Kadokawa, J. Formation of amylose-poly(tetrahydrofuran) inclusion complexes in ionic liquid media. Chem. Lett. 2011, 40, 31-33. [CrossRef]

9. Rachmawati, R.; Woortman, A.J.J.; Loos, K. Facile preparation method for inclusion complexes between amylose and polytetrahydrofurans. Biomacromolecules 2013, 14, 575-583. [CrossRef] [PubMed]

10. Kumar, K.; Woortman, A.J.J.; Loos, K. Synthesis of amylose-polystyrene inclusion complexes by a facile preparation route. Biomacromolecules 2013, 14, 1955-1960. [CrossRef] [PubMed]

11. Rachmawati, R.; Woortman, A.J.J.; Loos, K. Tunable properties of inclusion complexes between amylose and polytetrahydrofuran. Macromol. Biosci. 2013, 13, 767-776. [CrossRef] [PubMed]

12. Rachmawati, R.; Woortman, A.J.J.; Loos, K. Solvent-responsive behavior of inclusion complexes between amylose and polytetrahydrofuran. Macromol. Biosci. 2014, 14, 56-68. [CrossRef] [PubMed]

13. Kaneko, Y.; Kadokawa, J. Vine-twining polymerization: A new preparation method for well-defined supramolecules composed of amylose and synthetic polymers. Chem. Rec. 2005, 5, 36-46. [CrossRef] [PubMed]

14. Kaneko, Y.; Kadokawa, J. Synthesis of nanostructured bio-related materials by hybridization of synthetic polymers with polysaccharides or saccharide residues. J. Biomater. Sci. Polym. Ed. 2006, 17, 1269-1284. [CrossRef] [PubMed]

15. Kaneko, Y.; Kadokawa, J. Preparation of Polymers with Well-Defined Nanostructure in the Polymerization Field. In Modern Trends in Macromolecular Chemistry; Lee, J.N., Ed.; Nova Science Publishers Inc.: Hauppauge, NY, USA, 2009; pp. 199-217.

16. Kadokawa, J. Precision polysaccharide synthesis catalyzed by enzymes. Chem. Rev. 2011, 111, 4308-4345. [CrossRef] [PubMed]

17. Kadokawa, J. Preparation and applications of amylose supramolecules by means of phosphorylase-catalyzed enzymatic polymerization. Polymers 2012, 4, 116-133. [CrossRef]

18. Kadokawa, J. Architecture of amylose supramolecules in form of inclusion complexes by phosphorylase-catalyzed enzymatic polymerization. Biomolecules 2013, 3, 369-385. [CrossRef] [PubMed]

19. Kadokawa, J. Chemoenzymatic synthesis of functional amylosic materials. Pure Appl. Chem. 2014, 86, 701-709. [CrossRef]

20. Shoda, S.; Uyama, H.; Kadokawa, J.; Kimura, S.; Kobayashi, S. Enzymes as green catalysts for precision macromolecular synthesis. Chem. Rev. 2016, 116, 2307-2413. [CrossRef] [PubMed]

21. Ziegast, G.; Pfannemüller, B. Linear and star-shaped hybrid polymers. Phosphorolytic syntheses with di-functional, oligo-functional and multifunctional primers. Carbohydr. Res. 1987, 160, 185-204. [CrossRef]

22. Kitaoka, M.; Hayashi, K. Carbohydrate-processing phosphorolytic enzymes. Trends Glycosci. Glycotechnol. 2002, 14, 35-50. [CrossRef]

23. Yanase, M.; Takaha, T.; Kuriki, T. $\alpha$-Glucan phosphorylase and its use in carbohydrate engineering. J. Sci. Food Agric. 2006, 86, 1631-1635. [CrossRef]

24. Ohdan, K.; Fujii, K.; Yanase, M.; Takaha, T.; Kuriki, T. Enzymatic synthesis of amylose. Biocatal. Biotransform. 2006, 24, 77-81. [CrossRef]

25. Kadokawa, J. Precision synthesis of functional polysaccharide materials by phosphorylase-catalyzed enzymatic reactions. Polymers 2016, 8, 138. [CrossRef] 
26. Kadokawa, J.; Kaneko, Y.; Tagaya, H.; Chiba, K. Synthesis of an amylose-polymer inclusion complex by enzymatic polymerization of glucose 1-phosphate catalyzed by phosphorylase enzyme in the presence of polyTHF: A new method for synthesis of polymer-polymer inclusion complexes. Chem. Commun. 2001, 449-450. [CrossRef]

27. Kadokawa, J.; Kaneko, Y.; Nagase, S.; Takahashi, T.; Tagaya, H. Vine-twining polymerization: Amylose twines around polyethers to form amylose-Polyether inclusion complexes. Chem. Eur. J. 2002, 8, 3321-3326. [CrossRef]

28. Kadokawa, J.; Kaneko, Y.; Nakaya, A.; Tagaya, H. Formation of an amylose-polyester inclusion complex by means of phosphorylase-catalyzed enzymatic polymerization of $\alpha$-D-glucose 1-phosphate monomer in the presence of poly(e-caprolactone). Macromolecules 2001, 34, 6536-6538. [CrossRef]

29. Kadokawa, J.; Nakaya, A.; Kaneko, Y.; Tagaya, H. Preparation of inclusion complexes between amylose and ester-containing polymers by means of vine-twining polymerization. Macromol. Chem. Phys. 2003, 204, 1451-1457. [CrossRef]

30. Kaneko, Y.; Ueno, K.; Yui, T.; Nakahara, K.; Kadokawa, J. Amylose's recognition of chirality in polylactides on formation of inclusion complexes in vine-twining polymerization. Macromol. Biosci. 2011, 11, 1407-1415. [CrossRef] [PubMed]

31. Tanaka, T.; Sasayama, S.; Nomura, S.; Yamamoto, K.; Kimura, Y.; Kadokawa, J. An amylose-poly(L-lactide) inclusion supramolecular polymer: Enzymatic synthesis by means of vine-twining polymerization using a primer-guest conjugate. Macromol. Chem. Phys. 2013, 214, 2829-2834. [CrossRef]

32. Tanaka, T.; Sasayama, S.; Yamamoto, K.; Kimura, Y.; Kadokawa, J. Evaluating relative chain orientation of amylose and poly(L-lactide) in inclusion complexes formed by vine-twining polymerization using primer-guest conjugates. Macromol. Chem. Phys. 2015, 216, 794-800. [CrossRef]

33. Tanaka, T.; Tsutsui, A.; Gotanda, R.; Sasayama, S.; Yamamoto, K.; Kadokawa, J. Synthesis of amylose-polyether inclusion supramolecular polymers by vine-twining polymerization using maltoheptaose-functionalized poly(tetrahydrofuran) as a primer-guest conjugate. J. Appl. Glycosci. 2015, 62, 135-141. [CrossRef]

34. Tanaka, T.; Gotanda, R.; Tsutsui, A.; Sasayama, S.; Yamamoto, K.; Kimura, Y.; Kadokawa, J. Synthesis and gel formation of hyperbranched supramolecular polymer by vine-twining polymerization using branched primer-guest conjugate. Polymer 2015, 73, 9-16. [CrossRef]

35. Kadokawa, J.; Nomura, S.; Hatanaka, D.; Yamamoto, K. Preparation of polysaccharide supramolecular films by vine-twining polymerization approach. Carbohydr. Polym. 2013, 98, 611-617. [CrossRef] [PubMed]

36. Von Braunmühl, V.; Jonas, G.; Stadler, R. Enzymatic grafting of amylose from poly(dimethylsiloxanes). Macromolecules 1995, 28, 17-24. [CrossRef]

37. Smith, S.; Hubin, A.J. The preparation and chemistry of dicationically active polymers of tetrahydrofuran. J. Macromol. Sci. A Chem. 1973, 7, 1399-1413. [CrossRef]

38. Nomura, N.; Taira, A.; Tomioka, T.; Okada, M. A catalytic approach for cationic living polymerization: $\mathrm{Sc}(\mathrm{OTf})_{3}$-catalyzed ring-opening polymerization of lactones. Macromolecules 2000, 33, 1497-1499. [CrossRef]

39. Fan, Y.J.; Chen, G.P.; Tanaka, J.; Tateishi, T. L-Phe end-capped poly(L-lactide) as macroinitiator for the synthesis of poly(L-lactide)-b-poly(L-lysine) block copolymer. Biomacromolecules 2005, 6, 3051-3056. [CrossRef] [PubMed]

40. Bhuiyan, S.H.; Rus'd, A.A.; Kitaoka, M.; Hayashi, K. Characterization of a hyperthermostable glycogen phosphorylase from Aquifex aeolicus expressed in Escherichia coli. J. Mol. Catal. B Enzym. 2003, 22, 173-180. [CrossRef]

41. Yanase, M.; Takata, H.; Fujii, K.; Takaha, T.; Kuriki, T. Cumulative effect of amino acid replacements results in enhanced thermostability of potato type L $\alpha$-glucan phosphorylase. Appl. Environ. Microbiol. 2005, 71, 5433-5439. [CrossRef] [PubMed]

(C) 2017 by the authors. Licensee MDPI, Basel, Switzerland. This article is an open access article distributed under the terms and conditions of the Creative Commons Attribution (CC BY) license (http:/ / creativecommons.org/licenses/by/4.0/). 